Post-print version of the article

\title{
Different responses of taxonomic and functional structure of stream macroinvertebrate communities to local stressors and regional factors in a subtropical biodiversity hotspot
}

Zhengfei $\mathrm{Li}^{\mathrm{a}, \mathrm{c}}$, Jun Wang ${ }^{\mathrm{a}}$, Zhenyuan Liu ${ }^{\mathrm{a}, \mathrm{c}}$, Xingliang Meng ${ }^{\mathrm{a}}$, Jani heino ${ }^{\mathrm{d}}$, Xuankong Jiang ${ }^{\mathrm{a}, \mathrm{c}}$, Xiong Xiong $^{\mathrm{a}}$, Xiaoming Jiang ${ }^{\mathrm{a}, \mathrm{b}}$, Zhicai Xie ${ }^{\mathrm{a} *}$

a The Key Laboratory of Aquatic Biodiversity and Conservation, Institute of Hydrobiology, Chinese Academy of Sciences, Wuhan 430072, China

${ }^{b}$ State Key Laboratory of Eco-hydraulic in Northwest Arid Region of China, Xi'an University of Technology, Xi'an 710048, China

${ }^{\mathrm{c}}$ University of Chinese Academy of Sciences, Beijing 100049, China

${ }^{\mathrm{d}}$ Biodiversity Centre, Finnish Environment Institute, Paavo Havaksen Tie 3, P.O. Box 413, 90014 Oulu, Finland

\begin{abstract}
Examining the relative contribution of local environmental stressors and regional factors in structuring biological communities is essential for biodiversity conservation and environmental assessment, yet their relative roles for different community facets remain elusive. Here, we examined the responses of taxonomic and functional structure of stream macroinvertebrate communities to local and regional factors across a human-induced environmental gradient in the Han River Basin, one subtropical biodiversity hotspot in China. Our objectives were: 1) to examine if functional traits were as effective as traditional taxonomic measures in differentiating anthropogenic disturbances; 2) to compare the relative importance of environmental versus spatial variables and catchment-scale versus reach-scale variables for the two community facets. We found that both species and trait compositions performed well in differentiating anthropogenic disturbances, indicating that both taxonomic and functional structures of macroinvertebrate communities were altered by human activities. Particularly, traits including voltinism, development, adult life duration, dispersal ability, respiration, body size, rheophily, habit and trophic groups appeared to be
\end{abstract}


promising indicators of stream conditions. We found that environmental variables played more important role than spatial effects in structuring both taxonomic and functional facets of macroinvertebrate communities. Environmental filtering was more important in determining functional than taxonomic structure, and the opposite was true for spatial effects. In terms of environmental variables, catchment land-uses played the primary role in determining taxonomic composition, whereas reach-scale variables related to local habitat heterogeneity were more influential for functional structure. Our study highlights the importance of employing metacommunity perspectives and different community characterizations in both theoretical and applied research. For stream bioassessment and management, we argued that the combination of taxonomic and functional characterizations of community should be implemented, as different facets of biological communities responded to different types of anthropogenic disturbances.

Key wards: environmental stressors; spatial factors; taxonomic composition; functional structure; stream macroinvertebrates

\section{Graphical abstract}

Percentages of variation in taxonomic and functional structure explained by environmental variables versus spatial factors (a), and catchment versus reach scale environmental variables (b). The result of (b) is a further decomposition of the variance explained by environmental variables.
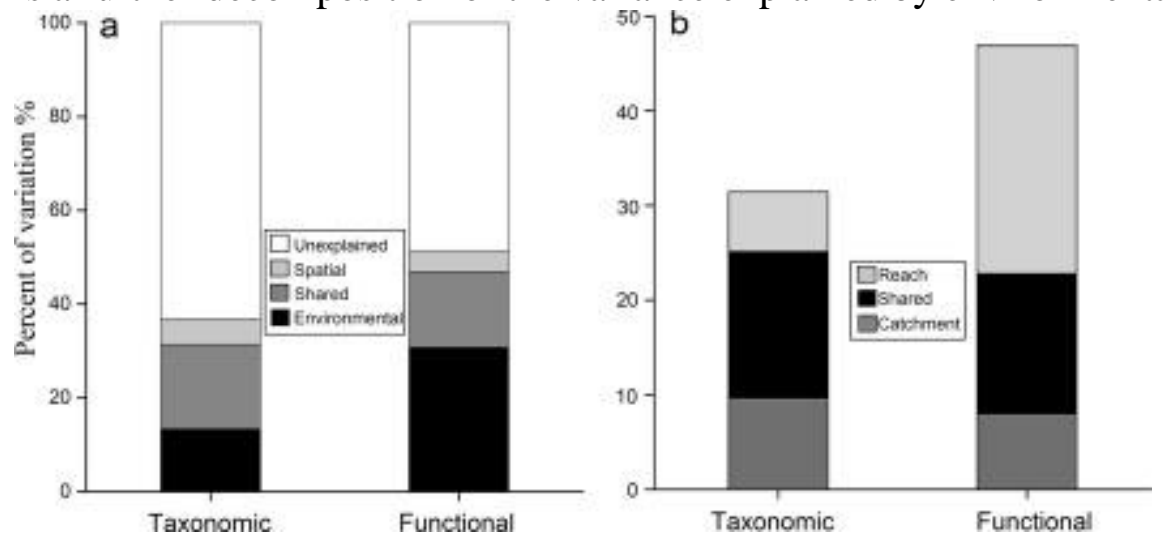

1. Download : Download high-res image (101KB)

2. Download : Download full-size image

\section{Introduction}

Global change impacts the biodiversity and functions of all ecosystems (Sala and Wall, 2000), and freshwater ecosystems, communities and species are severely jeopardized by anthropogenic impacts (Strayer and Dudgeon, 2010). Stream biological communities are thus profoundly threatened by multiple stressors caused by anthropogenic activities operating at a wide range of spatial and temporal scales 
(Larsen and Ormerod, 2013). Forecasting responses of stream biological communities to environmental stressors and changes therein can support a mechanistic approach for monitoring, managing and conserving biodiversity and ecosystems functions (Nd et al., 2015; Poff et al., 2010). Traditionally, main emphasis has been focused on the relationships between taxonomic measures (i.e., species composition and diversity indices) and local environmental variables. These studies have indeed revealed a remarkable variation in community structure along particular stressors, such as land-use practices (Helms et al., 2009), water eutrophication (Sandin and Johnson, 2000), and increased amounts of fine sediments (Richards and Bacon, 1994). However, taxonomic approaches do not allow the establishment of causal relationships between biological communities and stressors, and provide little information about ecosystem functioning (Dolédec et al., 2006; Menezes et al., 2010). New approaches for biomonitoring purposes are still required to assess the potential risks on stream ecosystems at different spatial scales.

In recent years, trait-based measures have received renewed attention as a promising approach in freshwater bioassessment (Heino, 2005; Menezes et al., 2010; Ning et al., 2017; Poff et al., 2010) because of several advantages: (1) Traits can be compared across multiple geographical regions that differ in their specific species composition, because the same traits are expressed by most species in the world (Heino et al., 2013b). (2) Traits also provide insights into the mechanisms causing observed changes in functional and structural characteristics of communities (Dolédec et al., 2006; Miserendino and Masi, 2010). Certain traits that affect ecosystem functions by influencing organismal performance, known as functional traits, were suggested to be a proxy of community functions in response to anthropogenic pressures (Menezes et al., 2010). This proxy of community function (hereafter, functional structure) should show a relatively stronger sensitiveness and a consistent response to environmental stressors, and it may do better in predicting changes in ecosystem functioning compared with taxonomic measures (Dolédec et al., 2006; Göthe et al., 2017; Tolonen et al., 2017).

Although previous studies emphasize the dominant role of local environmental conditions in driving community variations in freshwater ecosystems, it has been increasingly recognized that regional forces, such as spatial processes (relating to dispersal and other stochastic processes) strongly affect community structure and function (Cottenie, 2005; Heino et al., 2015; Ricklefs, 1987). Such perspectives are in accordance with the metacommunity concept, which aims to combine multiple ecological processes 
operating from local to regional scales into explaining the mechanisms of community assembly (Heino, 2013; Leibold et al., 2004). Therefore, teasing apart the relative importance of local filters and regional forces has become an important objective of metacommunity ecology, and neglecting the role of regional effects may result in overestimating or underestimating the importance of certain local factors in theoretical explorations and scientific practices (Cai et al., 2017; Liu et al., 2016). However, most studies mainly focused on examining the relative influence of local and regional factors on taxonomic measures, while functional metrics have been studied in the metacommunity context only relatively recently (Heino et al., 2007). Empirical evidence is still limited as few studies have directly compared the relative importance of focal ecological predictors on taxonomic versus functional structure simultaneously using the same metacommunity data and analytical approaches in stream ecosystems (Göthe et al., 2017).

Community characterizations based on taxonomy and functional traits should respond differently to the focal ecological drivers (Göthe et al., 2017). Generally, species composition is typically limited by the regional species pool, and might be determined by various ecological drivers, including local environmental conditions, species dispersal, climatic constraints and also some historical factors (Barrington, 1993; Schleuning et al., 2014). In contrast, functional structure should be most strongly related to environmental variables owing to the high correspondence between traits and environmental conditions (Ning et al., 2017; Townsend and Hildrew, 1994). Furthermore, environmental stressors at different hierarchical scales (e.g., reach and catchment scales) may contribute distinctly to different community characterizations (Tolonen et al., 2016). In addition, if taxonomic and functional structures are driven by different aspects or scales of environmental stressors, the two community characterizations may be complementary and should be considered simultaneously in bioassessment programs to discriminate multiple anthropogenic disturbances.

To better understand the mechanisms of community assembly and develop useful ecological indicators, we here examined the potential causes of the variations in taxonomic and functional structure of stream macroinvertebrate communities. Our study systems are located in the tributaries of the Han River, the largest tributary of the Yangtze River, China. These streams present strong environmental gradients and considerable habitat heterogeneity resulting from human disturbance and natural environmental conditions, thereby providing an ideal testing ground to explore roles of different drivers in 
structuring variation in stream biological communities. We aimed to assess the effects of human disturbances on taxonomic and functional structures, and then provide an integrated picture of the response of the two community characterizations to local and regional factors in the study area. In addition, we tested the following hypotheses: 1) functional structure should discriminate anthropogenic disturbance gradients as well as taxonomic structure; 2) both spatial factors and environmental variables at the catchment and reach scales play essential but different roles in determining taxonomic and functional structures. More specifically, we expected that functional structure should be primarily shaped by environmental variables, especially at the reach scale, while spatial factors and catchment scale variables should be more important for taxonomic than functional structure. We hope that this study would help assessing and predicting shifts in community structure and function under environmental stress situations, which may provide guidance for effective bioassessment and conservation of freshwater ecosystems.

\section{Materials and methods}

\subsection{Study area}

This study was located in the upstream headwaters of the Han River $\left(31^{\circ} 52^{\prime}-34^{\circ} 20^{\prime} \mathrm{N}, 106^{\circ} 09^{\prime}-\right.$ $118^{\circ} 47^{\prime} \mathrm{E}$ ), water source region of the Middle Route of the South to North Water Transfer Project (MRSNWTP) in China (Wang and Tan, 2017; Zhang et al., 2009). This region represents a transition area between northern-subtropical and warm-temperate regions with unique landscapes of geomorphology, making it one of the most important biodiversity hotspots in China. However, in recent years, this region has undergone a significant anthropogenic interference, such as a dramatic land-use change (e.g., a decline in native forest coverage, and an increase in the proportion of agricultural and urban land-uses), anabatic commercial sand dredging works, and strengthening water conservancy facilities (Li et al., 2009).

We sampled a total of 67 stream sites in 6 headwater streams of the Han River Basin during March and April 2017. This is the season when the majority of macroinvertebrates in streams are still in the larval stage in the study region. The descriptions of characteristics and main types of human disturbance in each stream are listed in the supplement file (Fig. A.1, Table A.1). These streams have suffered from various disturbances which can be used to reflect the main types and degrees of anthropogenic 
interference in the Han River Basin. We classified sampling sites into reference (Good), moderately disturbed (Fair), and severely disturbed (Poor) based on a comprehensive environmental disturbance score which was modified from Weigel and Dimick (2011. This score was a composite of six variables involving water quality variables (i.e. total phosphorus and total nitrogen), land use variables (agricultural and urban land percentage), flow regulation (dam and sand-mining) and historical point-source pollution (Table A.2), and was proved to be appropriate for describing the disturbance level of streams in this region (Jiang et al., 2017; Jiang et al., 2014). Nutrient concentrations for disturbance scores were based on the environmental quality standards for surface water of the People's Republic of China (GB 3838-2002) (MEP, 2002). Disturbance scores for TN and TP reflect the break points of Class II, Class III, Class IV and Class V water (water quality declines with increasing class). Disturbance scores for land-use, flow regulation and point-source pollution problems basically followed environmental classifications from Weigel and Dimick (2011. We thus identified a total of 18 reference sites, 24 moderately disturbed sites and the remaining 25 severely disturbed sites (Fig. 1).

\subsection{Macroinvertebrate sampling}

Benthic macroinvertebrates were obtained from three quantitative replicates using a Surber sampler $(30 \times 30 \mathrm{~cm}, 500 \mu \mathrm{m}$ mesh). The three samples covered most representative benthic microhabitats (usually riffles and pools) along a $100 \mathrm{~m}$ reach of each site. The samples were maintained in a low temperature incubator and then returned to the laboratory on the same day. The specimens were then hand-picked carefully from sediment on a white porcelain plate and later stored and preserved with $70 \%$ ethanol. We identified most macroinvertebrates using a stereo microscope (Stemi 508), and Oligochaeta and head capsules of Chironomidae using a microscope (Imager A2). Specimens were indentified to the lowest possible taxonomic level (usually genus or species) in the laboratory according to the relevant references (Brinkhurst, 1986; Dudgeon, 1999; Epler and Quality, 2001; Morse et al., 1994; Zhou et al., 2003). The three samples per site were pooled and then converted to density per square meter prior to the statistical analyses.

\subsection{Functional traits}

Twelve traits belonging to four trait groups (Life history, Mobility, Morphology and Ecology) for 
macroinvertebrates were selected and then subsequently divided into a total of 39 categories using a “fuzzy coding” approach (Table 1, see Usseglio-Polatera et al. 2000). These traits have previously been proved to be key traits responding sensitively to anthropogenic disturbance or natural environmental gradients (Díaz and Alonso, 2008; Miserendino and Masi, 2010; Saito et al., 2015), and thus they are suitable for the purposes of this study. Afterwards, we constructed a site $\times$ trait abundance matrix to represent community functional structure. This matrix was obtained by multiplying a species $\times$ trait matrix (e.g., 1 if a species displays a trait, 0 if not) by a site $\times$ species abundance matrix, and was widely used in previous studies to represent community functional composition (Poff et al., 2010; Strecker et al., 2011; Tolonen et al., 2017). We obtained species trait information mainly from published articles and other relevant literature (Poff et al., 2006; Usseglio - Polatera et al., 2000; Vieira et al., 2006).

\subsection{Environmental variables}

We measured reach-scale physical habitat variables at each site after macroinvertebrate sampling. Channel width (measured using a Ranger Finder instrument) and water depth (using a calibrated stick) were averaged from at least five equal transects. Current velocity (ms-1) was determined in the middle of the sampling location with a LJD-10 flow-meter. Water temperature and dissolved oxygen were measured with a WTW Multi 340i probe. Substratum was assigned into one of the five types: (i) Sand and silt $(<2$ mm), (ii) Gravel (2-32 mm), (iii) Pebble (32-64 mm), (iv) Cobble (64-256 mm), and (v) Boulder (>256 $\mathrm{mm}$ ), and their percentages were estimated at each site using a $1 \mathrm{~m}^{2}$ grid.

At each site, water chemical features were measured to represent water quality conditions. Turbidity, pH and conductivity were measured with an YSI6680 Multi-probe Water Quality Sonde. Then, water samples were collected and preserved in the field by acidification with concentrated $\mathrm{H}_{2} \mathrm{SO}_{4}$ and kept in a cool box for laboratory determination of chemical composition. Eight chemical variables including total nitrogen $(\mathrm{TN})$, nitrate nitrogen $\left(\mathrm{NO}_{3}\right)$, nitrite nitrogen $\left(\mathrm{NO}_{2}\right)$, ammonium nitrogen $\left(\mathrm{NH}_{4}\right)$, total phosphorus (TP), soluble reactive phosphate (SRP), chemical oxygen demand (CODMn) and soluble silicon ( $\mathrm{Si}$ ) were analyzed according to the standards provided by Wei et al. (1989) and Huang et al. (1999).

We delineated the sub-basin area for each sample site by ArcGIS 10.3 (Esri, Inc.) using Digital 
Elevation Models (DEM) with 30m resolution which provided by the Chinese Academy of Sciences (http://www.cnic.cn/) for land use analysis. For each sample site, land use data used included available remote sensing images of Landsat images, Sentinel 2 and ASTER with $30 \mathrm{~m}$ resolution. The images were then interpreted and expressed as the percentage of seven principal land use types (i.e. forest, agriculture, grassland, urban, open water, bare land and "others") using ENVI 5.3 (Exelis Visual Information Solutions, Inc.) within a sub-basin, and the map's overall classification accuracy is more than $85 \%$ (Huang et al., 2016). We also calculated land-use diversity using Shannon-Weaver index based on the proportions of the land-use variables (Liu et al., 2016).

\subsection{Spatial factors}

We used a spatial eigenfunction approach (Borcard and Legendre, 2002) based on overland distances among sampling sites to create Moran's Eigenvector Maps (MEMs) as spatial predictors (Dray et al., 2006). The MEMs represents the spatial configuration of sample units using principal coordinates of a truncated (nearest neighbors only) among samples distance matrix and the coordinates with positive eigenvalues were retained as spatial variables in the subsequent analyses (Gilbert and Bennett, 2010). MEMs with high eigenvalues represent broad-scale geographical/spatial patterns, and low eigenvalues represent fine-scale geographical/spatial patterns in species distributions. We only measured overland distances by considering the lesser hydrological connections in the whole study area and that spatial eigenvectors based on either straight-line or watercourse distances may provide similar information about spatial effects on community structures (Grönroos et al., 2013; Heino et al., 2017). MEM analysis was carried out in the R environment, using the "pcnm" function from the vegan package (Oksanen et al., 2013).

\subsection{Data analysis}

One-way analysis of variance (ANOVA) was used to detect the differences of environmental variables (both reach and catchment scales), taxonomic metrics (i.e. abundance and relative abundance of higher taxa) and functional metrics (i.e. trait relative abundance) among the three condition-based site groups. These comparisons were carried out with Tukey's honestly significant difference (HSD) post hoc tests. In cases of persistent heteroscedasticity (i.e. if results of Levene's test were significant), we performed Games-Howell tests which do not assume equal variances between groups (Beckmann et al., 
2005).

Canonical analysis of principal coordinates (CAP, Anderson and Robinson, 2003) was performed to identify average differences in environmental conditions, taxonomic composition and functional structure among the three site groups. CAP is a variant of principal coordinates analysis (PCOA) which can find axes through the multivariate cloud of points that best discriminate among a priori groups (Anderson et al., 2008). This analysis can be based on any type of resemblance matrix, and we thus used Euclidean distance for environmental data, and Bray-Curtis similarity for species and trait abundance data to determine variations between the three condition-based site groups. Prior to CAPs, biological and environmental parameters were also $\log (\mathrm{x}+1)$ transformed and standardized. Then, we ran the diagnostics test in CAP to guarantee the number of PCO axes leading to the best discrimination among site groups, and tested the null hypothesis that group centroids do not differ by using 999 permutations (Heino et al., 2013a).

Distance-based redundancy analysis (dbRDA) based on Bray-Curtis dissimilarity on $\log (\mathrm{x}+1)$ transformed abundance data was performed to examine relationships between biology metrics (using taxonomic and trait abundance data) and key ecological drivers. First, non-normal environmental variables, except $\mathrm{pH}$, were $\log (\mathrm{x}+1)$ transformed to improve their normality before data analysis, and highly correlated variables (Pearson's $r>0.75$ ) from each set of environmental variables were removed (Table A.3). Second, a forward selection using the function "ordiR2step" in vegan was conducted on the two sets of environmental variables (i.e., catchment and reach scale) and spatial (MEMs) factors separately to select a minimum set of variables with significant contributions $(\mathrm{P}<0.05$, after 999 random permutations) to explaining variation in taxonomic and functional composition (Oksanen et al., 2013). Forward selection was carried out only if the global test including all explanatory variables of a variable group was significant. Forward selection was conducted with two stopping rules: the adjusted $\mathrm{R}^{2}$ value of the reduced model exceeded that of the global model or the critical $p$ value $(p=0.05)$ was exceeded. Finally, we used a hierarchical partitioning of variance approach to determine how variation in taxonomic and functional structures was explained by spatial factors versus environmental variables and then by catchment-scale versus reach-scale environmental variables (See also Liu et al., 2016; Poff et al., 2010). The total percentage of variation explained in taxonomic and functional structures was thus divided into 
unique and shared fractions accounted for by each set of ecological predictors. We reported adjusted $\mathrm{R}^{2}$ of pure and shared contributions of the spatial and environmental variables from the constrained ordinations, because of their impartiality and strong recommendation in previous studies (Peres-Neto et al., 2006). We also tested for the significance of pure fractions of each set of predictor variables by means of 999 permutations at a significance level of $\alpha=0.05$ using the function "anova" in the package vegan (PeresNeto et al., 2006). We ran all univariate ANOVAs using the SPSS statistical program (version 22.0), CAP analyses using the PERMANOVA+ for PRIMER 6.0, and dbRDA analyses and variation partitioning with the vegan package in $\mathrm{R}$ (Oksanen et al., 2013).

\section{Results}

\subsection{Environmental variables}

CAP analysis revealed a significant distinction of the environmental characteristics among the three site groups (Fig. 2a, Table 2), confirming that the site classification was broadly reliable. Significant differences were detected for 20 variables (one-way ANOVAs, all $\mathrm{p}<0.05$ ) among three site groups, including water quality, physical habitats, and land use factors (Table 2). Four water chemical variables (COD, TP, $\mathrm{PO}_{3}$ and $\mathrm{NO}_{2}$ ), five land use variables (LD, \% Agriculture, \% Open water, \% Urban and \% others), and six physical habitat variables (i.e., EC, WT, Turb, WD, \% Gravel and \% Sand) were markedly higher at the disturbed sites than at the reference sites. On the contrary, only two water physical-chemical variable (DO and $\mathrm{pH})$, one land use variable (\% Forest) and two coarse substrates (\% Boulder and $\%$ cobble) were pronouncedly higher at the reference sites than at the disturbed sites. There were no significant differences among the three site groups for the remaining environmental variables $(\mathrm{p}>0.05)$.

\subsection{Benthic taxonomic composition}

A total of 227 taxa were identified, belonging to five phyla, nine classes and 82 families. Aquatic insects contributed $86 \%$ of the total richness (Table A.4), with Ephemeroptera (41.7\% of total abundance, 26 taxa overall), Chironomidae $(20.1 \%, 65)$ and Trichoptera $(15.6 \%, 36)$ as the taxonomically and numerically richest taxonomic groups. Baetidae (Baetis sp. and Baetiella sp.), Heptageniidae (Rhithrogena sp.) and Chironomidae (Orthocladius sp. and Polypedilum sp.) were the most common and abundant families in the study streams. 
CAP analysis indicated that taxonomic structure of macroinvertebrate communities differed distinctly among the three groups (Fig. 2b), and the percentage classification of sites to their parent group was $76.7 \%$ (Table 2). There was significant difference in species richness and total abundance among three site groups (One-way ANOVA, p < 0.05) (Table 3). Also, significant differences were detected in the relative abundance of higher taxa and the most abundant families (Table 3). Generally, good and fair sites had a significantly higher abundance of sensitive insects, e.g., Plecoptera (Perlidae spp.) and Trichoptera taxa (Glossosomatidae spp.) than poor ones, whereas poor sites exhibited the highest abundance of Chironomidae, Oligochaeta and Mollusca $(\mathrm{p}<0.05$, Table 3). No significant differences were detected for the density of Ephemeroptera $(\mathrm{F}=2.501, \mathrm{p}=0.090)$ and Coleoptera $(\mathrm{F}=0.696, \mathrm{p}=$ 0.502) in our study.

\subsection{Functional trait structure}

According to CAP analysis, functional structure of macroinvertebrate communities also differed among the three groups (Fig. 2c), with the percentage correct classifications reaching $70.8 \%$ (Table 2). A total of 21 categories belonging to nine traits differed significantly among three site groups (Fig. 3, Table A.5). For life history traits, good sites exhibited a significantly higher abundance of taxa characterized by the traits "Univoltine", "Slow seasonal developed" and "< 1month", while disturbed sites had markedly more individuals within the trait categories "Bi- or multivoltine", "Fast seasonal development" and "< 1weak". Two morphology traits including "Body size" and "Respiration" differed significantly among groups: taxa with the traits "Small" and "Large" body size, "Respiration Tegument" and "Air (valve, trachea, gas film)" were more inclined to occur in poor sites, while taxa with "Medium" size and breathing using "Gills" occurred more frequently at good and fair sites. Only one mobility trait (i.e., Dispersal ability) differed markedly among groups: good and fair sites showed a significantly higher abundance of weak dispersing taxa, while poor sites had significantly more individuals with strong dispersal ability. In terms of ecology traits, taxa favoring "Depositional" habitats were more abundant in poor sites, while "Erosional" species were mainly distributed in good and fair sites. Furthermore, poor sites revealed a much higher abundance of taxa possessed "Burrow" and "Sprawl" habits and were always "Collector"; however, good sites had significantly more individuals in the habit "Cling" and within the trait category "Filterer". There were no significant differences among the three site groups for the 
remaining traits including “Armoring”, "Occurrence in drift", "Swimming ability” and "Body shape”.

\subsection{Key environmental and spatial factors affecting community structures}

For taxonomic composition, six catchment-scale variables (i.e., \% agriculture, $\%$ forest, $\%$ open water, $\%$ grass, $\%$ urban and \% others), eight reach-scale variables (EC, CODmn, water temperature, $\mathrm{NH}_{4}, \mathrm{NO}_{3}, \%$ pebble, TP and DO), and eight spatial factors related to both broad (MEM1-5 and MEM8) and fine (MEM21 and MEM26) geographical patterns were selected for further analyses (Table 5). For functional structure, three variables ( $\%$ agriculture, $\%$ forest and $\%$ urban) from the catchment-scale, six variables (\% pebble, $\mathrm{NO}_{3}, \%$ gravel, $\mathrm{DO}$, current velocity and mean depth) from the reach-scale, and four spatial factors (MEM1, MEM21, MEM26 and MEM8) were retained and subsequently used in variation partitioning process (Table 5).

\subsection{Relative roles of environmental versus spatial and catchment versus reach scale variables for community structures}

Variation partitioning showed that spatial factors and environmental variables at reach- and catchment-scales were all important in explaining variation in macroinvertebrate assemblages, yet their relative roles varied among different community descriptions (Fig. 5). For species composition, a total of $34.9 \%$ of the variation could be explained by the selected environmental and spatial variables based on the adjusted $\mathrm{R}^{2}$ values. Environmental variables explained more of the variation in community structure $(11.3 \%)$ compared to spatial factors $(3.4 \%)$. In terms of environmental variables, the variation was more effectively explained by catchment- scale variables $(9.7 \%)$ compared to the reach-scale variables $(6.3 \%)$.

For functional structure, the retained variables accounted for $51.4 \%$ of the total variation, and environmental variables explained more of the variation $(30.8 \%)$ compared to spatial factors $(4.4 \%)$. Partitioning of environmental variables showed that, reach-scale variables played more important roles $(24.2 \%)$ over catchment-variables $(8.0 \%)$ for functional structure.

Remarkably, all the pure fractions were significant $(p<0.05)$ after accounting for the effects of the other predictor variable set, implying that each set of predictor variables involved in our study were significant for the response data (taxonomic and functional structures). Furthermore, the shared effects of each set of ecological factors also accounted for a considerable percent of variation (from $14.8 \%$ to $20.1 \%$ ) in both taxonomic and functional structures. 


\section{Discussion}

\subsection{Effects of anthropogenic disturbances on taxonomic versus functional structure}

Recent research on perturbed streams has shown that the structural and functional attributes of stream communities are strongly affected by anthropogenic activities (Dolédec et al., 2006; Dolédec et al., 2011; Menezes et al., 2010; Miserendino and Masi, 2010; Saito et al., 2015). Our results supported the findings of these previous studies, as both taxonomic and functional structure could discriminate different anthropogenic disturbance-related site groups. In accordance with traditional bioassessment practices, taxonomic metrics including species richness, abundance and relative abundance of some dominant groups dramatically varied along disturbance gradients (Mccabe and Gotelli, 2000; Nd et al., 2015). Specifically, significant decreases in the abundance of some Ephemeroptera, Plecoptera and Trichoptera (EPT) taxa and increases of Chironomidae, Oligochaeta and Mollusca in association with disturbance intensity have been reported elsewhere in freshwater bioassessment studies (Cooper et al., 2009; Dolédec et al., 2006; Jun et al., 2011; Rosa et al., 2014). The variation of taxonomic composition indeed provides guidance for biomonitoring work; however, integrating trait-based information into community analysis can enhance the understanding of mechanisms causing observed changes in functional and structural characteristics of biological communities (Dolédec et al., 2006; Heino, 2011).

In terms of functional structure, half of the categories belonging to nine traits differed significantly among disturbance-based site groups, and these traits are therefore good candidates for inclusion in measures of stream condition. Particularly, species with traits that favor high resistance or resilience capacity to degraded habitat conditions, such as multivoltinism, fast development time, short life span, small body size and flexible mobility predominated in highly disturbed sites. These species are typically recognized as r-strategists (Southwood, 1977), exhibiting less dependency on stable environments, and have been recorded to be abundant in various disturbed systems, such as agricultural streams (Dolédec et al., 2006), pesticide-polluted rivers (Schäfer et al., 2007) and sand-dredging lakes (Meng et al., 2018). In contrast, univoltine species developing slower and having larger body size, longer life span and weaker mobility, known as K-strategists, were more abundant in the reference sites, showing relatively higher dependency on stable environments with a low intensity of disturbance to maintain populations (Oschmann, 1988). 
Respiratory mode embodies the adaptation of benthic fauna to dissolved oxygen (DO) in the water column (Chapman et al., 2004). Previous studies have shown that species with tegument respiration are more resistant to lower DO levels than species with gill respiration (Feio and Dolédec, 2012). Other studies also argued that species with aerial respiration are independent of DO, and degraded stream habitats favor aerial respiration (Scheinin et al., 2001). Our results fully agreed with the above perspectives as poor sites with lower DO level were more associated with species showing aerial and tegument respiration compared with the good and fair sites which were dominated by species with gill respiration. "Rheophily" and "Habit" are always related to the conditions of physical habitat that species live in, such as bottom substrates (Ning et al., 2017; Pollard and Yuan, 2010). In our study, poor sites exhibited significantly higher percent of fine sediments (i.e., sand and clay) than good and fair sites (with more percent of coarse substrate), mainly owing to the adverse effects of land-use practices (e.g., agriculture) in this basin. Species prefering fine sediments are more inclined to burrow into or sprawl on the surface of these bottoms, while taxa favoring coarse substrates may be more likely to cling on relatively stable bottoms to avoid being washed away (Morse et al. 1994). Anthropogenic disturbance (e.g., agricultural land use) also affect the balance of functional feeding groups by altering organic matter inputs and in-stream production (Dolédec et al., 2011; Menezes et al., 2010). It has been well documented that collectors and filterers dominate habitats subjected to high levels of human disturbances, reflecting the relatively high amounts of fine particulate organic matter in both sediment and water column of such localities (Miserendino and Masi, 2010). We indeed found a higher abundance of collectors in poor sites, but a higher proportion of filterers were detected in the good and fair sites (Fig 3). This finding may partially because the main filterers in our study are caddisflies (e.g., Hydropsychidae and Brachycentridae) who need stable coarse substrate to attach their nets and cases (Statzner, 2011). Therefore, future research in both theoretical and applied fields should also consider the interplay and trade-offs between trait modalities as well as focusing on the responses of single trait.

\subsection{The effects of environmental versus spatial factors on community structures}

Understanding how environmental stressors and spatial factors structuring freshwater biological assemblages is not only of theoretical interest but also important within the field of applied ecology (Heino, 2013). Consistent with current understanding of headwater streams, environmental variables 
played more important roles than spatial factors for both community characterizations (Göthe et al., 2017; Heino et al., 2012; Landeiro et al., 2012; Rádková et al., 2014). Specifically, as the streams in our study area covered a wide range of natural and human-induced environmental gradients, this finding could be explained by the high environmental variation or habitat harshness which provided a large scope for environmental filtering (Liu et al., 2016). As we expected, environmental variables indeed explained larger fractions of variance in functional than taxonomic structure, and the opposite was true for spatial factors (Fig 5a). These results indicated a more sensitive response of functional structure to environmental variations compared to traditional taxonomic metrics, a feature also observed by others (Dolédec et al., 2011; Göthe et al., 2017; Pollard and Yuan, 2010). This finding was not surprising because environmental conditions sort species to coexist in local communities via specific combinations of traits but not species identity per se, supporting the concept of habitat templets (Southwood, 1977; Townsend and Hildrew, 1994).

Spatial factors were also detected to play important roles for benthic macroinvertebrate communities, indicating that dispersal processes were important for community assembly (Brederveld et al., 2011; Grönroos et al., 2013). Furthermore, spatial variables were more important, although only marginally, for taxonomic than functional structure (Fig $5 \mathrm{~b}$ ). This is because congeneric species always possess similar traits, causing a high consistency and stability in functional composition along geographical gradients, while species composition rests on species pools and should document high species turnover, resulting from spatial limitation (Heino et al., 2007; Statzner et al., 2004). In this context, our result that spatial factors also played essential roles in determining functional structure was consistent with findings from other empirical studies (Erös et al., 2009; Göthe et al., 2017; Poff et al., 2010). The detected spatial effects on functional structure in our study may be either explained by the distributions of individual species and the consequent differences in functional traits (Heino, 2005), or because the spatial distribution of some environmental factors that filter species with suitable traits is spatially patterned or limited to a certain spatial scale (Ning et al., 2017).

\subsection{The effects of catchment versus reach scale variables on community structures}

Our study showed that macroinvertebrate communities were hierarchically structured by environmental variables at both catchment and reach scales, which was consistent with the hierarchy 
theory (O'Neill et al., 1989) and the landscape filtering hypothesis (Poff, 1997). Also, the two community characterizations responded differently to each set of predictor variables at catchment and reach scales.

Environmental factors influenced taxonomic structure, which is most evident at the catchment scale, as was also found in our study. Catchment land-use practices strongly affect community structure either by directly altering basin hydrological regimes and further modifying local physical habitats, or indirectly through changing nutrient concentrations in streams (Castro et al., 2018; Robinson et al., 2014; Shilla and Shilla, 2011). Generally, increasing land use intensity (e.g., agricultural intensification and urbanization) would heavily degrade benthic communities (Kasangaki et al., 2008; Wang et al., 2018), while pristine land use patterns (e.g., forest vegetation coverage) may boost the number and density of species, especially those of specialist species (Börschig et al., 2013; Silva-Junior and Moulton, 2011). Therefore, catchment-scale variables could shape the pool of species that may potentially occur in a local community, thereby strongly influencing local community structure (Weijters et al., 2010).

Contrary to the case of taxonomic structure, functional structure was mainly influenced by reachscale variables. Such finding was likely owing to the greater proximity of reach-scale variables to the organisms, which provides immediate filtering effects for traits compared with large-scale variables like land-use practices (Richards et al., 1997). Reach-scale variables related to physical habitats (i.e., bottom substrates, $\mathrm{DO}, \mathrm{Vel}$ and $\mathrm{MD})$ were selected in the dbRDA models prior to water nutrient $\left(\mathrm{NO}_{3}\right)$, implying the importance of physical habitat heterogeneity for trait variation. This result was reasonable because some traits used in our study are the reflections of habitat conditions, such as respiratory modes for DO level, rheophily and habits for bottom substrates and occurrence in drift for current velocity (Chapman et al., 2004; Ning et al., 2017; Richards et al., 1997). Moreover, this finding also supported the coexistence theory that habitat heterogeneity provides opportunities for niche partitioning and thus allows species with different specialized niches to coexist and maintain viable populations in local communities (Stark et al., 2017).

\subsection{Implications for Environmental Assessment}

A main challenge of employing biological data for environmental assessment is the selection of biological metrics showing utility to discriminate anthropogenic impact. Our results revealed that functional traits of stream macroinvertebrate assemblages provide an alternative, or perhaps a 
complementary way, to taxonomic approaches in differentiating anthropogenic disturbance in stream ecosystems. Among the traits involved, the ones related to life history (i.e., voltinism, development and adult life duration), mobility (dispersal ability), morphology (respiration and body size) and ecology (rheophily, habit and trophic groups) were good candidates to assess anthropogenic impacts on streams.

Most bioassessment programs are generally based on the assumption that variations in biological assemblages are mostly determined by local environmental conditions (Cai et al., 2017; Heino, 2013). The roles of spatial processes that may strongly affect biological communities are generally ignored, which may bias the assessments of ecological status based on biological metrics (Heino et al., 2015). However, our present study highlighted that spatial factors are important for variation in both taxonomic and functional structure. Hence, spatial processes should also be taken into account to improve the assessment of human impacts on stream ecosystems (Liu et al., 2016). Improved bioassessment approaches should thus discriminate the signal due to human disturbance from the natural variations, such as those caused by dispersal processes (Heino et al., 2015).

Some previous studies argued that trait-based measures should act as more time-saving and economic approaches over taxonomy-based measures, implying that a high resolution of species identification may not always be necessary in future stream biomonitoring practices (Árva et al., 2016; Dolédec et al., 2000; Menezes et al., 2010). However, the two community characterizations in our study responded differently to the focal environmental stressors, with taxonomic structure being primarily determined by catchment land-uses and functional structure being more strongly controlled by local habitat conditions. In other words, different community characterizations should show distinct sensitivity towards various human interferences prevailing at different spatial scales. Thus, we cannot fully support the idea that using one community characterization (i.e., taxonomic or functional) as a surrogate of the other in developing bioassessment and management strategies. In contrast, freshwater bioassessment should adopt an integrative approach embracing different community features to monitor and assess the potential impacts of human induced environmental changes on biological communities.

\section{Conclusion}

Understanding the relationship between different ecological drivers and community characterizations today may help in predicting the possible changes in the community structure and ecosystem functions of 
streams in the future. In general, our study illustrated that both taxonomic and functional measures of macroinvertebrate communities are good indicators for assessing ecological quality in degraded stream ecosystems. In addition, the relative importance of each set of predictor variables (i.e., spatial vs. environmental and catchment vs. reach) depends on the biological facet employed (taxonomic or functional). Such findings highlight the importance of using different facets of biological communities in metacommunity analysis and environmental assessment. Therefore, we argue that this study has strong implications for freshwater bioassessment in this study area in particular and for other regions in general.

\section{Acknowledgements}

We are grateful to Dr. Yintao Jia, Dr. Chengrong Peng, Kang Chen and Shun Huang who assisted in sampling work and measurement of environmental parameters. This work was supported by the National Natural Science Foundation of China (No.

31400469, 41571495), the National Science and Technology Basic Research Program (No. 2015FY110400-4), Program for Biodiversity Protection (2017HB2096001006).

\section{Reference}

Anderson MJ, Gorley RN, Clarke KR. PERMANOVA+ for primer: Guide to software and statistical methods. 2008.

Anderson MJ, Robinson J. Generalized discriminant analysis based on distances. Australian \& New Zealand Journal of Statistics 2003; 45: 301-318.

Árva D, Tóth M, Mozsár A, Specziár A. The roles of environment, site position, and seasonality in taxonomic and functional organization of chironomid assemblages in a heterogeneous wetland, Kis-Balaton (Hungary). Hydrobiologia 2016; 787: 1-21.

Barrington DS. Ecological and Historical Factors in Fern Biogeography. Journal of Biogeography 1993; 20: 275-279.

Beckmann MC, Schöll F, Matthaei CD. Effects of increased flow in the main stem of the River Rhine on the invertebrate communities of its tributaries. Freshwater Biology 2005; 50: 10-26. 
Borcard D, Legendre P. All-scale spatial analysis of ecological data by means of principal coordinates of neighbour matrices. Ecological Modelling 2002; 153: 51-68.

Börschig C, Klein AM, Wehrden HV, Krauss J. Traits of butterfly communities change from specialist to generalist characteristics with increasing land-use intensity. Basic \& Applied Ecology 2013; 14: 547-554.

Brederveld RJ, Jähnig SC, Lorenz AW, Brunzel S, Soons MB. Dispersal as a limiting factor in the colonization of restored mountain streams by plants and macroinvertebrates. Journal of Applied Ecology 2011; 48: 12411250.

Brinkhurst RO. Guide to the freshwater aquatic microdrile oligochaetes of North America. Canada. Spec. Publ. Fish. Aquat. Sci. 1986; 84

Cai Y, Xu H, Vilmi A, Tolonen KT, Tang X, Qin B, et al. Relative roles of spatial processes, natural factors and anthropogenic stressors in structuring a lake macroinvertebrate metacommunity. Science of the Total Environment 2017; s 601-602: 1702-1711.

Castro DMPD, Dolédec S, Callisto M. Land cover disturbance homogenizes aquatic insect functional structure in neotropical savanna streams. Ecological Indicators 2018; 84: 573.

Chapman LJ, Schneider KR, Apodaca C, Chapman CA. Respiratory ecology of macroinvertebrates in a swamp-river system of east Africa. Biotropica 2004; 36: 572-585.

Cooper MJ, Rediske RR, Uzarski DG, Burton TM. Sediment contamination and faunal communities in two subwatersheds of Mona Lake, Michigan. Journal of Environmental Quality 2009; 38: 1255.

Cottenie K. Integrating environmental and spatial processes in ecological community dynamics. Ecology Letters 2005; 8: 1175-1182.

Díaz AM, Alonso MLS. Biological traits of stream macroinvertebrates from a semi-arid catchment: patterns along complex environmental gradients. Freshwater Biology 2008; 53: 1-21.

Dolédec S, Olivier JM, Statzner B. Accurate description of the abundance of taxa and their biological traits in stream invertebrate communities: effects of taxonomic and spatial resolution. Archiv Fur Hydrobiologie 2000; 148: 25-43.

Dolédec S, Phillips N, Scarsbrook M, Riley RH, Townsend CR. Comparison of structural and functional approaches to determining landuse effects on grassland stream invertebrate communities. Journal of the North American Benthological Society 2006; 25: 44-60.

Dolédec S, Phillips N, Townsend C. Invertebrate community responses to land use at a broad spatial scale: trait and 
taxonomic measures compared in New Zealand rivers. Freshwater Biology 2011; 56: 1670-1688.

Dray S, Legendre P, Peres-Neto PR. Spatial modelling: a comprehensive framework for principal coordinate analysis of neighbour matrices (PCNM). Ecological Modelling 2006; 196: 483-493.

Dudgeon D. Tropical Asian streams: zoobenthos, ecology and conservation. Vol 1: Hong Kong University Press, 1999.

Epler JH, Quality NCDoW. Identification Manual for the Larval Chironomidae (Diptera) of North and South Carolina: A Guide to the Taxonomy of the Midges of the Southeastern United States, Including Florida: St. Johns River Water Management District, 2001.

Erös T, Heino J, Schmera D, Rask M. Characterising functional trait diversity and trait-environment relationships in fish assemblages of boreal lakes. Freshwater Biology 2009; 54: 1788-1803.

Feio MJ, Dolédec S. Integration of invertebrate traits into predictive models for indirect assessment of stream functional integrity: A case study in Portugal. Ecological Indicators 2012; 15: 236-247.

Gilbert B, Bennett JR. Partitioning variation in ecological communities: do the numbers add up? Journal of Applied Ecology 2010; 47: 1071-1082.

Göthe E, Baattrup-Pedersen A, Wiberg-Larsen P, Graeber D, Kristensen EA, Friberg N. Environmental and spatial controls of taxonomic versus trait composition of stream biota. Freshwater Biology 2017; 62.

Grönroos M, Heino J, Siqueira T, Landeiro VL, Kotanen J, Bini LM. Metacommunity structuring in stream networks: roles of dispersal mode, distance type, and regional environmental context. Ecology \& Evolution 2013; 3: 4473-4487.

Heino J. Functional biodiversity of macroinvertebrate assemblages along major ecological gradients of boreal headwater streams. Freshwater Biology 2005; 50: 1578-1587.

Heino J. A macroecological perspective of diversity patterns in the freshwater realm. Freshwater Biology 2011; 56: 1703-1722.

Heino J. The importance of metacommunity ecology for environmental assessment research in the freshwater realm. Biological Reviews 2013; 88: 166-178.

Heino J, Alahuhta J, Ala-Hulkko T, Antikainen H, Bini LM, Bonada N, et al. Integrating dispersal proxies in ecological and environmental research in the freshwater realm. Environmental Reviews 2017; 25: 334-349.

Heino J, Grönroos M, Ilmonen J, Karhu T, Niva M, Paasivirta L. Environmental heterogeneity and $\beta$ diversity of stream macroinvertebrate communities at intermediate spatial scales. Freshwat. Sci. 2013a; 32: $142-154$. 
Heino J, Grönroos M, Soininen J, Virtanen R, Muotka T. Context dependency and metacommunity structuring in boreal headwater streams. Oikos 2012; 121: 537-544.

Heino J, Melo AS, Siqueira T, Soininen J, Valanko S, Bini LM. Metacommunity organisation, spatial extent and dispersal in aquatic systems: patterns, processes and prospects. Freshwater Biology 2015; 60: 845-869.

Heino J, Mykra H, Kotanen J, Muotka T. Ecological filters and variability in stream macroinvertebrate communities: do taxonomic and functional structure follow the same path? Ecography 2007; 30: 217-230.

Heino J, Schmera D, Erős T. A macroecological perspective of trait patterns in stream communities. Freshwater Biology 2013b; 58: 1539-1555.

Helms BS, Schoonover JE, Feminella JW. Seasonal variability of landuse impacts on macroinvertebrate assemblages in streams of western Georgia, USA. Journal of the North American Benthological Society 2009; 28: 9911006.

Huang C, Zhou Z, Wang D, Dian Y. Monitoring forest dynamics with multi-scale and time series imagery. Environmental Monitoring \& Assessment 2016; 188: 273.

Huang XF, Chen W, Cai QH. Standard Methods for Observation andAnalysis in Chinese Ecosystem Research Networke Survey, Observation andAnalysis of Lake Ecology. Standards Press of China, Beijing (in Chinese). 1999; : .

Jiang X, Song Z, Xiong J, Proctor H, Xie Z. Different surrogacy approaches for stream macroinvertebrates in discriminating human disturbances in Central China. Ecological Indicators 2017; 75: 182-191.

Jiang X, Song Z, Xiong J, Xie Z. Can excluding non-insect taxa from stream macroinvertebrate surveys enhance the sensitivity of taxonomic distinctness indices to human disturbance? Ecological Indicators 2014; 41: 175182.

Jun YC, Kim NY, Kwon SJ. Effects of land use on benthic macroinvertebrate communities: Comparison of two mountain streams in Korea. Annales de Limnologie - International Journal of Limnology 2011; 47: S35-S49.

Kasangaki A, Chapman LJ, Balirwa J. Land use and the ecology of benthic macroinvertebrate assemblages of highaltitude rainforest streams in Uganda. Freshwater Biology 2008; 53: 681-697.

Landeiro VL, Bini LM, Melo AS, Pes AMO, Magnusson WE. The roles of dispersal limitation and environmental conditions in controlling caddisfly (Trichoptera) assemblages. Freshwater Biology 2012; 57: 1554-1564.

Larsen S, Ormerod SJ. Anthropogenic modification disrupts species co-occurrence in stream invertebrates. Global Change Biology 2013; 20: 51-60. 
Leibold MA, Holyoak M, Mouquet N, Amarasekare P, Chase JM, Hoopes MF, et al. The Metacommunity Concept: A Framework for Multi-Scale Community Ecology. Ecology Letters 2004; 7: 601-613.

Li S, Gu S, Tan X, Zhang Q. Water quality in the upper Han River basin, China: the impacts of land use/land cover in riparian buffer zone. Journal of Hazardous Materials 2009; 165: 317-324.

Liu S, Xie G, Wang L, Cottenie K, Liu D, Wang B. Different roles of environmental variables and spatial factors in structuring stream benthic diatom and macroinvertebrate in Yangtze River Delta, China. Ecological Indicators 2016; 61: 602-611.

Mccabe DJ, Gotelli NJ. Effects of disturbance frequency, intensity, and area on assemblages of stream macroinvertebrates. Oecologia 2000; 124: 270-279.

Menezes S, Baird DJ, Soares AMVM. Beyond taxonomy: A review of macroinvertebrate trait-based community descriptors as tools for freshwater biomonitoring. Journal of Applied Ecology 2010; 47: 711-719.

Meng X, Jiang X, Li Z, Wang J, Cooper KM, Xie Z. Responses of macroinvertebrates and local environment to shortterm commercial sand dredging practices in a flood-plain lake. Science of the Total Environment 2018; 631: 1350-1359.

Ministry of Environmental Protection. Ministry of Environmental Protection, 2002. Environmental quality standard for surface water (GB3838-2002). : http://english.mep.gov.cn/standards reports/standards/water environment/quality standard/200710/t20071024111792.htm, 2002.

Miserendino $\mathrm{ML}$, Masi $\mathrm{Cl}$. The effects of land use on environmental features and functional organization of macroinvertebrate communities in Patagonian low order streams. Ecological Indicators 2010; 10: 311-319.

Morse JC, Yang L, Tian L. Aquatic insects of China useful for monitoring water quality: Hohai University Press, 1994.

Nd HT, Whiles MR, Royer TV, David MB. Relationships between water quality, habitat quality, and macroinvertebrate assemblages in Illinois streams. Journal of Environmental Quality 2015; 36: 1653-1660.

Ning D, Yang W, Zhou Y, González-Bergonzoni I, Jie Z, Kai C, et al. Different responses of functional traits and diversity of stream macroinvertebrates to environmental and spatial factors in the Xishuangbanna watershed of the upper Mekong River Basin, China. Science of the Total Environment 2017; 574: 288-299.

O'Neill RV, Johnson AR, King AW. A hierarchical framework for the analysis of scale. Landscape Ecology 1989; 3: 193-205.

Oksanen J, Blanchet FG, Kindt R, Legendre P, Minchin PR, O'Hara RB, et al. Vegan: Community Ecology Package. R Package Version. 2.0-10. Journal of Statistical Software 2013; 48: 1-21. 
Oschmann W. Upper Kimmeridgian and Portlandian marine macrobenthic associations from southern England and northern France. Facies 1988; 18: 49-82.

Peres-Neto, Legendre P, Dray S, Borcard D. Variation partitioning of species data matrices: estimation and comparison of fractions. Ecology 2006; 87: 2614-2625.

Poff LR. Landscape filters and species traits: towards mechanistic understanding and prediction in stream ecology. Journal of the North American Benthological Society 1997; 16: 391-409.

Poff LR, Pyne MI, Bledsoe BP, Cuhaciyan CC, Carlisle DM. Developing linkages between species traits and multiscaled environmental variation to explore vulnerability of stream benthic communities to climate change. Journal of the North American Benthological Society 2010; 29: 1441-1458.

Poff NL, Olden JD, Vieira NK, Finn DS, Simmons MP, Kondratieff BC. Functional trait niches of North American lotic insects: traits-based ecological applications in light of phylogenetic relationships. Journal of the North American Benthological Society 2006; 25: 730-755.

Pollard Al, Yuan LL. Assessing the consistency of response metrics of the invertebrate benthos: a comparison of trait- and identity-based measures. Freshwater Biology 2010; 55: 1420-1429.

Rádková V, Bojková J, Křoupalová V, Schenková J, Syrovátka V, Horsák M. The role of dispersal mode and habitat specialisation in metacommunity structuring of aquatic macroinvertebrates in isolated spring fens. Freshwater Biology 2014; 59: 2256-2267.

Richards C, + RH, Johnson L, Host G. Catchment and reach-scale properties as indicators of macroinvertebrate species traits. Freshwater Biology 1997; 37: 219-230.

Richards C, Bacon KL. Influence of fine sediment on macroinvertebrate colonization of surface and hyporheic stream substrates. The Great Basin Naturalist 1994: 106-113.

Ricklefs RE. Community Diversity: Relative Roles of Local and Regional Processes. Science 1987; 235: 167-171.

Robinson CT, Schuwirth N, Baumgartner S, Stamm C. Spatial relationships between land-use, habitat, water quality and lotic macroinvertebrates in two Swiss catchments. Aquatic Sciences 2014; 76: 375-392.

Rosa BJFV, Rodrigues LFT, Oliveira GSD, Alves RDG. Chironomidae and Oligochaeta for water quality evaluation in an urban river in southeastern Brazil. Environmental Monitoring \& Assessment 2014; 186: 7771-9.

Saito VS, Siqueira T, Fonseca-Gessner AA. Should phylogenetic and functional diversity metrics compose macroinvertebrate multimetric indices for stream biomonitoring? Hydrobiologia 2015; 745: 167-179.

Sala OE, Wall DH. Global biodiversity scenarios for the year 2100. Science 2000; 287: 1770-1774. 
Sandin L, Johnson RK. The statistical power of selected indicator metrics using macroinvertebrates for assessing acidification and eutrophication of running waters. Assessing the Ecological Integrity of Running Waters. Springer, 2000, pp. 233-243.

Schäfer RB, Caquet T, Siimes K, Mueller R, Lagadic L, Liess M. Effects of pesticides on community structure and ecosystem functions in agricultural streams of three biogeographical regions in Europe. Science of the Total Environment 2007; 382: 272.

Scheinin B, Lindgren L, Rosenberg PH. Perspectives for biomonitoring at large spatial scales: a unified measure for the functional composition of invertebrate communities in European running waters. Basic \& Applied Ecology 2001; 2: 73-85.

Schleuning M, Ingmann L, Strauß R, Fritz SA, Dalsgaard B, Matthias Dehling D, et al. Ecological, historical and evolutionary determinants of modularity in weighted seed-dispersal networks. Ecology Letters 2014; 17: 454-463.

Shilla DJ, Shilla DA. The effects of catchment land use on water quality and macroinvertebrate assemblages in Otara Creek, New Zealand. Chemistry \& Ecology 2011; 27: 445-460.

Silva-Junior EF, Moulton TP. Ecosystem Functioning and Community Structure as Indicators for Assessing Environmental Impacts: Leaf Processing and Macroinvertebrates in Atlantic Forest Streams. International Review of Hydrobiology 2011; 96: 656-666.

Southwood TR. Habitat, the templet for ecological strategies? The Journal of Animal Ecology 1977: 337-365.

Stark J, Lehman R, Crawford L, Enquist BJ, Blonder B. Does environmental heterogeneity drive functional trait variation? A test in montane and alpine meadows. Oikos 2017; 126.

Statzner B. Mineral grains in caddisfly pupal cases and streambed sediments: assessing resource use and its limitation across various river types. Annales de Limnologie - International Journal of Limnology 2011; 47: 103-118.

Statzner B, Dolédec S, Hugueny B. Biological Trait Composition of European Stream Invertebrate Communities: Assessing the Effects of Various Trait Filter Types. Ecography 2004; 27: 470-488.

Strayer DL, Dudgeon D. Freshwater biodiversity conservation: recent progress and future challenges. Journal of the North American Benthological Society 2010; 29: 344-358.

Strecker AL, Casselman JM, Fortin MJ, Jackson DA, Ridgway MS, Abrams PA, et al. A multi-scale comparison of trait linkages to environmental and spatial variables in fish communities across a large freshwater lake. 
Oecologia 2011; 166: 819-831.

Tolonen KE, Leinonen K, Marttila H, Erkinaro J, Heino J. Environmental predictability of taxonomic and functional community composition in high-latitude streams. Freshwater Biology 2017; 62.

Tolonen KE, Tokola L, Grönroos M, Hjort J, Kärnä OM, Erkinaro J, et al. Hierarchical decomposition of trait patterns of macroinvertebrate communities in subarctic streams. Freshwater Science 2016; 35.

Townsend CR, Hildrew AG. Species traits in relation to a habitat templet for river systems. Freshwater Biology 1994; 31: 265-275.

Usseglio-Polatera P, Bournaud M, Richoux P, Tachet H. Biological and ecological traits of benthic freshwater macroinvertebrates: relationships and definition of groups with similar traits. Freshwater Biology 2000; 43: $175-205$.

Vieira NK, Poff N, Carlisle DM, Moulton S, Koski ML, Kondratieff BC. A database of lotic invertebrate traits for North America. US Geological Survey Data Series 2006; 187: 1-15.

Wang Q, Roß-Nickoll M, Wu D, Deng W, Wang Z, Yuan X, et al. Impervious area percentage predicated influence of rapid urbanization on macroinvertebrate communities in a southwest China river system. Science of the Total Environment 2018; 627: 104-117.

Wang X, Tan X. Macroinvertebrate community in relation to water quality and riparian land use in a substropical mountain stream, China. Environmental Science \& Pollution Research 2017; 24: 14682-14689.

Wei FS, Kou HR, Hong SJ. Methods for the Examination of Water andWastewater. China Environmental Science Press, Beijing (in Chinese). 1989.

Weigel BM, Dimick JJ. Development, validation, and application of a macroinvertebrate-based Index of Biotic Integrity for nonwadeable rivers of Wisconsin. Journal of the North American Benthological Society 2011; 30: $665-679$.

Weijters MJ, Janse JH, Alkemade R, Verhoeven JTA. Quantifying the effect of catchment land use and water nutrient concentrations on freshwater river and stream biodiversity. Aquatic Conservation Marine \& Freshwater Ecosystems 2010; 19: 104-112.

Zhang Q, Xu Z, Shen Z, Li S, Wang S. The Han River watershed management initiative for the Southto-North Water Transfer project (Middle Route) of China. Environmental Monitoring \& Assessment 148(1-4. 2009.

Zhou C, Gui H, Zhou K. Larval Key to Families of Ephemeroptera from China (Insecta). Journal of Nanjing Normal University 2003; 26: 65-68. 
Figures:
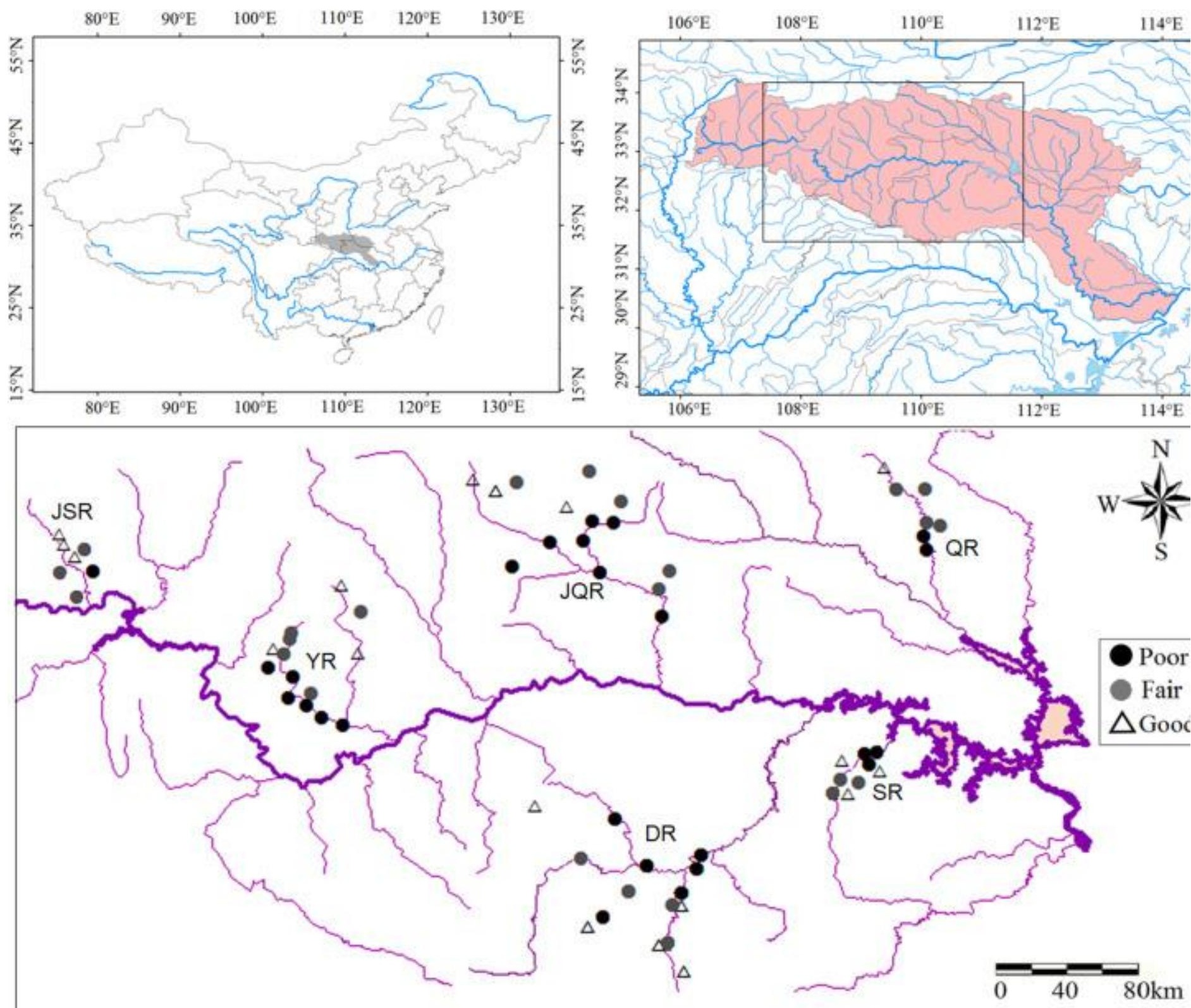

1. Download : Download high-res image (652KB)

2. Download : Download full-size image

Fig. 1. Location of the Han River Basin in China and the distribution of 67 sampling sites in the study area. Open triangles, gray circles and dark circles represent reference (Good), moderately disturbed (Fair) and severely disturbed (Poor) sites, respectively. 

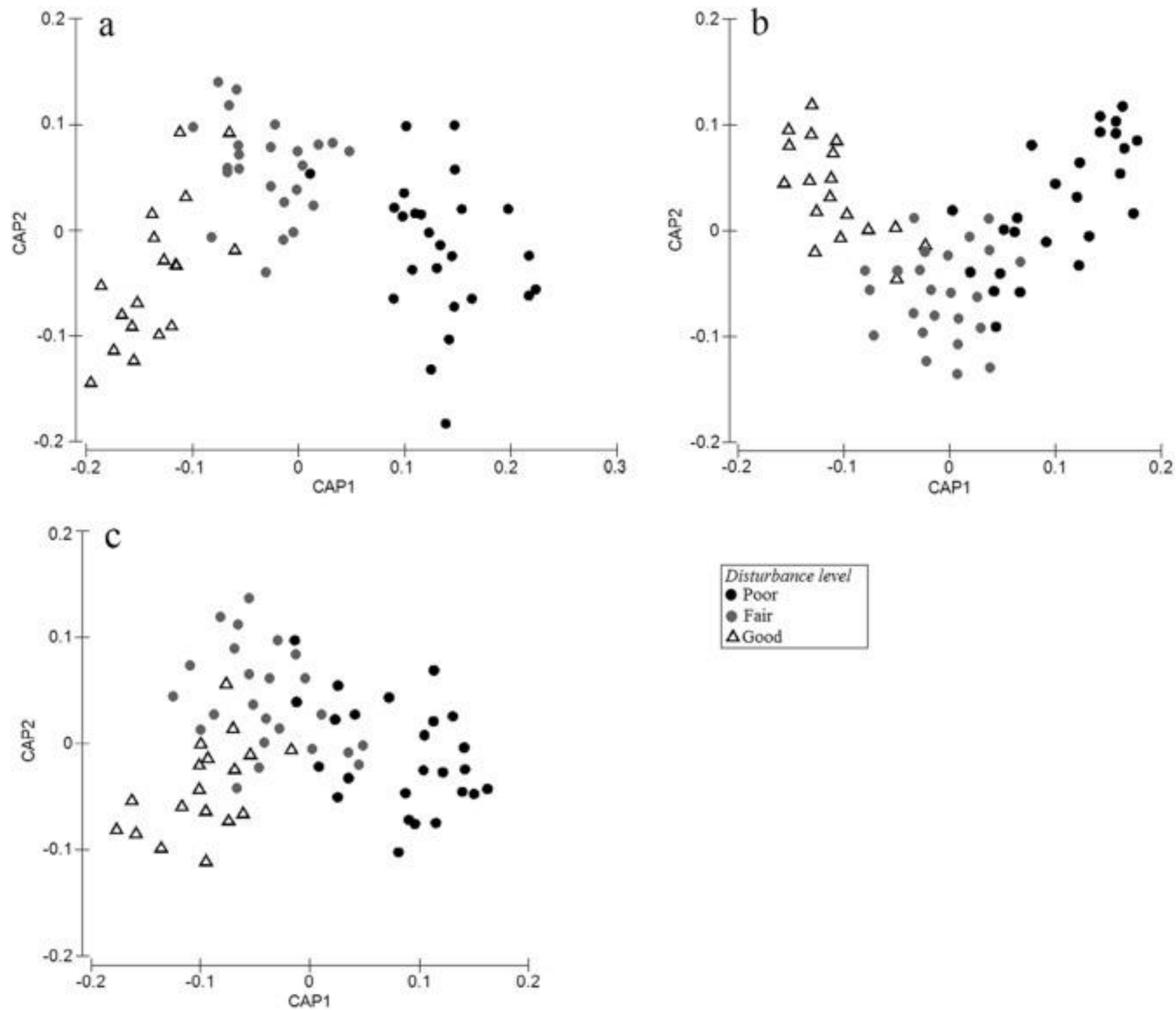

Disturbance level
- Poor
- Fair
$\Delta$ Good

1. Download : Download high-res image (128KB)

2. Download: Download full-size image

Fig. 2. Canonical analysis of principal coordinates (CAP) ordination plots based on environmental variables (a) using Euclidean distance, and taxonomic (b) and functional (c) abundance datasets using Bray-Curtis similarity matrices. 

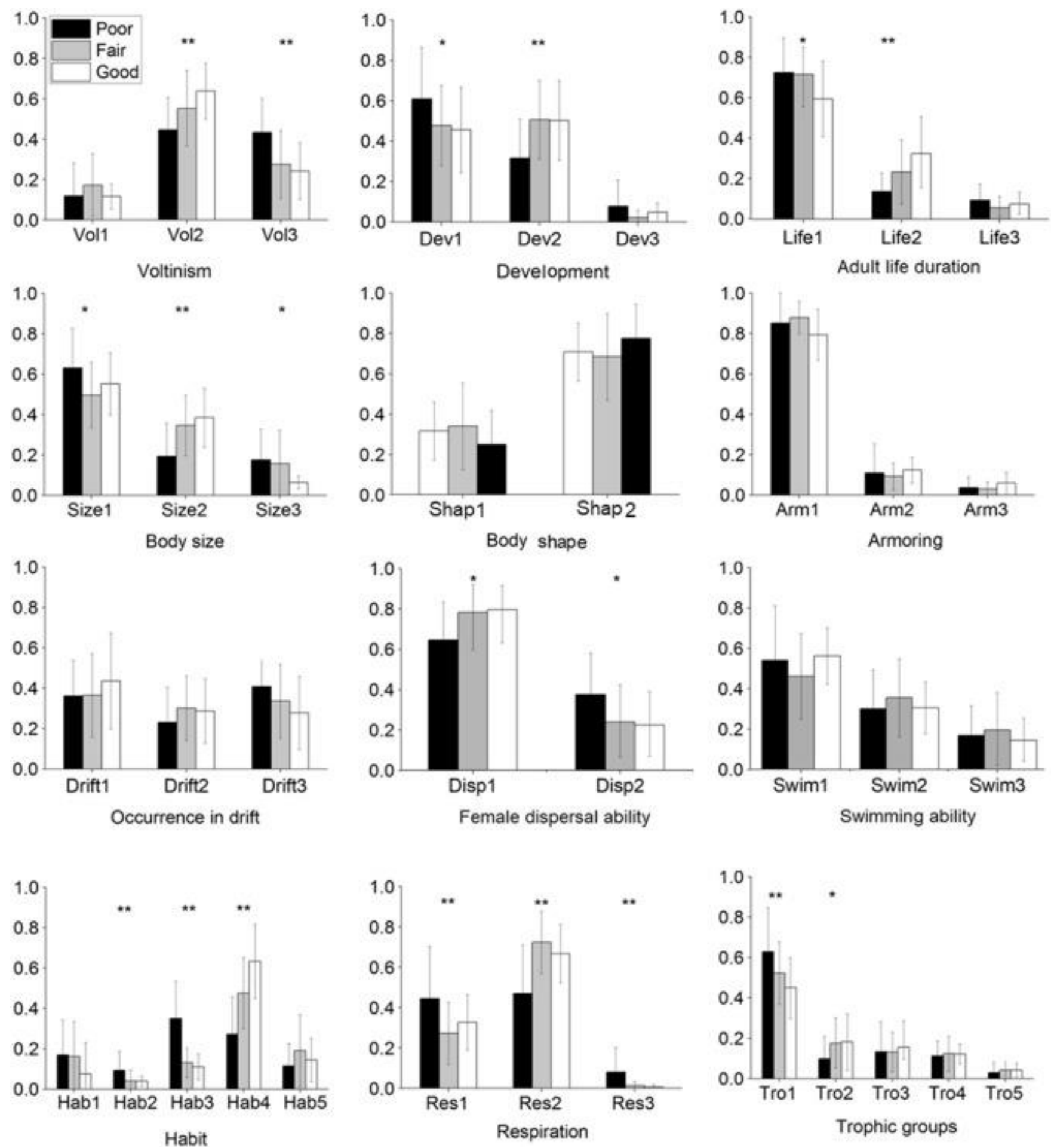

1. Download : Download high-res image (246KB)

2. Download: Download full-size image

Fig. 3. The structure of 39 categories of twelve traits at poor (black), fair (gray) and good (white) site groups. Each bar represents the mean percentage with standard deviation of each trait category in three site groups. The ratio is the abundance of species with the same trait to the total abundance ratio in a sample. All the category codes in each trait refer to Table 1 . * Significance level at $p<0.05$, $* *$ significance level at $\mathrm{p}<0.01$. 

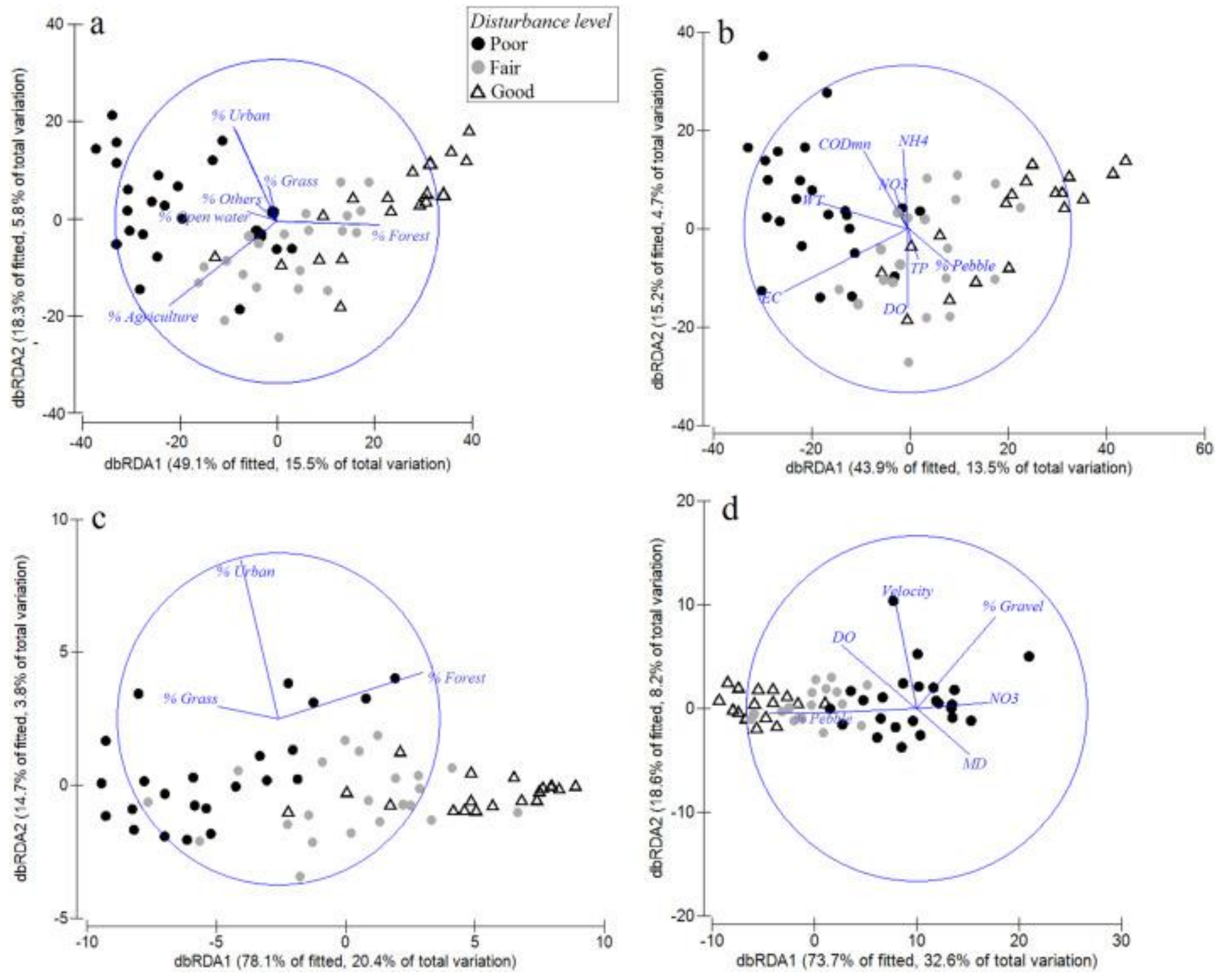

1. Download : Download high-res image (734KB)

2. Download: Download full-size image

Fig. 4. Constrained ordination (dbRDA) of taxonomic composition ( $a$ and $b$ ) and functional structure (c and d) of benthic macroinvertebrate assemblages in 67 stream sites. The significant environmental variables ( $\mathrm{a}$ and $\mathrm{c}$ show the catchment-scale, and $\mathrm{b}$ and $\mathrm{d}$ show the reach-scale variables) were selected using forward selection $(\mathrm{p}<0.05)$. Abbreviations for environmental variables are listed in Table 1. 

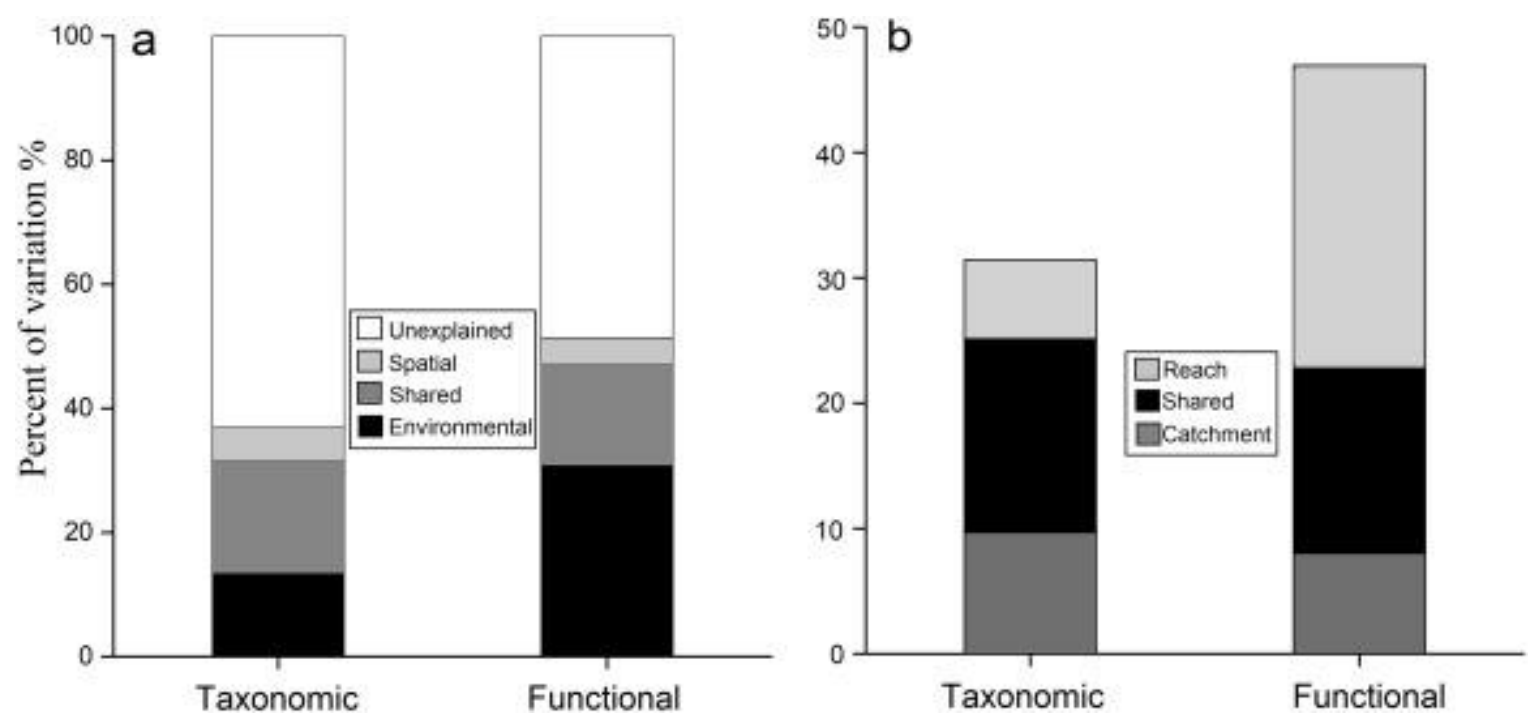

1. Download : Download high-res image (150KB)

2. Download : Download full-size image

Fig. 5. Percentages of variation in taxonomic and functional structure explained by environmental variables versus spatial factors (a), and catchment versus reach scale environmental variables (b). The result of (b) is a further decomposition of the variance explained by environmental variables 
Tables:

Table 1. Functional trait classification of benthic macroinvertebrate in the tributaries of upper Han River.

$\begin{array}{lll}\text { Trait } & \text { Trait state } & \text { Code }\end{array}$

Life history

\begin{tabular}{cll}
\multirow{2}{*}{ Voltinism } & Semivoltine $(<1$ generation/y) & Vol1 \\
& Univoltine (1 generation/y) & Vol2 \\
& Bi- or multivoltine ( $>$ 1 generation $/ \mathrm{y})$ & Vol3 \\
& Fast seasonal & Dev1 \\
Development & Slow seasonal & Dev2 \\
& Non seasonal & Dev3 \\
& $<1$ week & Life1 \\
Adult life duration & $<1$ month & Life2 \\
& $>1$ month & Life3 \\
& Small $(<9 \mathrm{~mm})$ & Size1 \\
Body size & Medium $(9-16 \mathrm{~mm})$ & Size2 \\
& Large $(>16 \mathrm{~mm})$ & Size3
\end{tabular}

Resistance and resilience

\begin{tabular}{|c|c|c|}
\hline \multirow{3}{*}{ Body shape } & Streamlined (flat, fusiform) & Shap1 \\
\hline & Not streamlined (cylindrical, round, or bluff) & Shap2 \\
\hline & None (soft-bodied forms) & Arm1 \\
\hline \multirow[t]{3}{*}{ Armoring } & Poor (heavily sclerotized) & Arm2 \\
\hline & Good (e.g., some cased caddisflies) & Arm3 \\
\hline & Rare (catastrophic only) & Drif1 \\
\hline \multirow[t]{3}{*}{ ccurrence in drift } & t Common (typically observed) & Drif2 \\
\hline & Abundant (dominant in drift samples) & Drif3 \\
\hline & None & Swim1 \\
\hline \multirow[t]{2}{*}{ wimming ability } & Weak & Swim2 \\
\hline & Strong & Swim3 \\
\hline \multirow{4}{*}{ dult flying ability } & Weak (e.g., cannot fly into light breeze) & Fly 1 \\
\hline & Strong & Fly 2 \\
\hline & Climb & Hab1 \\
\hline & Burrow & Hab2 \\
\hline \multirow[t]{3}{*}{ Habit } & Sprawl & Hab3 \\
\hline & Cling & Hab4 \\
\hline & Swim & Hab5 \\
\hline
\end{tabular}

General biological characteristics

\begin{tabular}{lll}
\multirow{2}{*}{ Respiration type } & Respiration Tegument & Res1 \\
\cline { 2 - 3 } & Gills & Res2 \\
& Collector & Res3 \\
& Filterer feeder & Tro1 \\
Trophic groups & Herbivore (scraper, piercer, and shedder) & Tro2 \\
\cline { 2 - 3 } & Prodator (piercer and engulfer) & Tro4 \\
& Shredder (detritivore) & Tro5
\end{tabular}

(Mainly modified from $\underline{\text { Poff et al., 2006) }}$ 
Table 2. Summary of the results of Canonical analysis of principal coordinates (CAP) analysis for average differences in environmental variables, and taxonomic (species) and functional (trait) composition of macroinvertebrate communities among the three site groups. Trace $=$ sum of the canonical eigenvalues, delta $=$ the 1 st eigenvalue. $p$-Values (in parentheses) were based on 999 permutations.

Poor Fair Good Total \% Correct \% Total correct Trace (p) Delta (p)

Environment

$\begin{array}{lllllll}\text { Poor 20 } & 5 & 0 & 25 & 80.0 & & \\ \text { Fair 0 } & 20 & 4 & 24 & 83.3 & 80.6 & 1.22(0.001) 0.88(0.001) \\ \text { Good 0 } & 4 & 14 & 18 & 77.8 & & \\ \text { Species } & & & & & & \\ \text { Poor 19 } & 6 & 0 & 25 & 76.0 & & 1.34(0.001) 0.83(0.001) \\ \text { Fair 3 } & 17 & 4 & 24 & 70.8 & 76.7 & \\ \text { Good 0 } & 3 & 15 & 18 & 83.3 & & \\ \text { Traits } & & & & & & \\ \text { Poor 17 } & 8 & 0 & 25 & 68.0 & & 0.68(0.001) 0.62(0.001) \\ \text { Fair 3 } & 16 & 5 & 24 & 66.7 & 70.8 & \\ \text { Good 0 } & 4 & 14 & 18 & 77.8 & & \end{array}$


Table 3. Mean value and SD of environmental variables at three site groups in the Han River Basin.

\begin{tabular}{|c|c|c|c|c|c|c|}
\hline \multirow{2}{*}{\multicolumn{7}{|c|}{ Reach scale }} \\
\hline & & & & & & \\
\hline Conductivity (s/cm) ${ }^{\square}$ & EC & $188.64 \pm 73.82$ & $223.93 \pm 88.27$ & $324.96 \pm 85.23$ & 14.257 & $>0.001$ \\
\hline Dissolved oxygen (mg/L) & DO & $10.77 \pm 1.02$ & $10.23 \pm 0.61$ & $9.56 \pm 2.18$ & 5.895 & 0.004 \\
\hline Water temperature $\left({ }^{\circ} \mathrm{C}\right)^{\square}$ & WT & $13.29 \pm 2.16$ & $13.44 \pm 2.07$ & $16.28 \pm 2.85$ & 10.52 & $<0.001$ \\
\hline $\mathrm{pH}^{\square}$ & $\mathrm{pH}$ & $8.64 \pm 0.43$ & $8.61 \pm 0.30$ & $8.35 \pm 0.37$ & 4.268 & 0.019 \\
\hline Turbidity ${ }^{\square}$ & Turbidity & $3.60 \pm 3.24$ & $22.77 \pm 4.65$ & $103.79 \pm 213.04$ & 3.457 & 0.037 \\
\hline Width $(\mathrm{m})^{-}$ & WD & $13.38 \pm 10.59$ & $20.33 \pm 16.73$ & $33.61 \pm 28.61$ & 4.317 & 0.018 \\
\hline Mean depth (m) & MD & $0.22 \pm 0.06$ & $0.20 \pm 0.07$ & $0.33 \pm 0.30$ & 3.067 & 0.054 \\
\hline Current velocity (m/s) & Velocity & $0.69 \pm 0.20$ & $0.54 \pm 0.16$ & $0.59 \pm 0.39$ & 1.187 & 0.312 \\
\hline Percentage of Boulder $\square$ & $\%$ Boulder & $17.31 \pm 9.49$ & $9.29 \pm 6.49$ & $2.44 \pm 4.02$ & 23.432 & $<0.001$ \\
\hline Percentage of Cobble ${ }^{\square}$ & $\%$ Cobble & $30.77 \pm 11.15$ & $31.25 \pm 6.95$ & $17.96 \pm 11.40$ & 13.248 & $3<0.001$ \\
\hline Percentage of Pebble & \% Pebble & $22.15 \pm 6.41$ & $24.79 \pm 8.27$ & $19.88 \pm 7.98$ & 2.425 & 0.097 \\
\hline Percentage of Gravel ${ }^{-}$ & $\%$ Gravel & $18.31 \pm 8.74$ & $19.83 \pm 4.97$ & $28.48 \pm 8.65$ & 11.49 & $<0.001$ \\
\hline Percentage of Sand and clay $\square$ & \% Sand and clay & $11.46 \pm 12.40$ & $14.83 \pm 12.60$ & $31.24 \pm 19.59$ & 9.449 & $<0.001$ \\
\hline Chemical oxygen demand $(\mathrm{mg} / \mathrm{L})^{-}$ & COD & $1.89 \pm 0.54$ & $2.09 \pm 0.59$ & $3.70 \pm 1.61$ & 17.005 & $5<0.001$ \\
\hline Total phosphorus (mg/L) & TP & $0.03 \pm 0.02$ & $0.05 \pm 0.05$ & $0.21 \pm 0.28$ & 6.206 & 0.004 \\
\hline Phosphate (mg/L) ${ }^{\square}$ & $\mathrm{PO}_{3}$ & $0.02 \pm 0.04$ & $0.03 \pm 0.03$ & $0.10 \pm 0.15$ & 3.941 & 0.025 \\
\hline Nitrate (mg/L) & $\mathrm{NO}_{3}$ & $1.58 \pm 0.85$ & $1.93 \pm 1.10$ & $2.16 \pm 1.00$ & 1.395 & 0.256 \\
\hline Nitrite $(\mathrm{mg} / \mathrm{L})^{-}$ & $\mathrm{NO}_{2}$ & $0.01 \pm 0.01$ & $0.01 \pm 0.01$ & $0.02 \pm 0.02$ & 4.366 & 0.017 \\
\hline Ammonium nitrogen $(\mathrm{mg} / \mathrm{L})$ & $\mathrm{NH}_{4}$ & $0.40 \pm 0.29$ & $0.44 \pm 0.31$ & $0.52 \pm 0.35$ & 0.647 & 0.527 \\
\hline Total nitrogen $(\mathrm{mg} / \mathrm{L})$ & TN & $1.99 \pm 0.67$ & $2.37 \pm 0.93$ & $2.69 \pm 0.99$ & 2.61 & 0.082 \\
\hline \multicolumn{7}{|l|}{ Catchment scale } \\
\hline Catchment area $\left(\mathrm{km}^{2}\right)$ & CA & $174.83 \pm 184.28$ & $582.60 \pm 100.38$ & $8306.56 \pm 692.65$ & 1.782 & 0.177 \\
\hline Land-use diversity ${ }^{\square}$ & LD & $1.17 \pm 0.09$ & $1.27 \pm 0.12$ & $1.47 \pm 0.15$ & 27.45 & $<0.001$ \\
\hline Percentage of Agriculture ${ }^{\square}$ & $\%$ Agriculture & $7.14 \pm 4.34$ & $11.83 \pm 7.45$ & $18.54 \pm 8.23$ & 11.588 & $3<0.001$ \\
\hline Percentage of Forest ${ }^{-}$ & $\%$ Forest & $80.10 \pm 16.14$ & $73.12 \pm 17.18$ & $60.60 \pm 14.29$ & 7.481 & 0.001 \\
\hline Percentage of Grassland & $\%$ Grass & $12.14 \pm 14.69$ & $13.98 \pm 13.09$ & $17.67 \pm 14.54$ & 0.784 & 0.461 \\
\hline Percentage of Open water $\square$ & $\%$ Open water & $0.06 \pm 0.07$ & $0.07 \pm 0.08$ & $0.47 \pm 0.41$ & 16.277 & $7<0.001$ \\
\hline Percentage of Urban ${ }^{-}$ & $\%$ Urban & $0.17 \pm 0.22$ & $0.33 \pm 0.33$ & $1.46 \pm 2.27$ & 4.98 & 0.01 \\
\hline Percentage of Bare land & $\%$ Bare land & $0.23 \pm 0.36$ & $0.39 \pm 0.34$ & $0.73 \pm 0.91$ & 3.041 & 0.055 \\
\hline Percentage of Others & $\%$ Others & $0.15 \pm 0.016$ & $0.28 \pm 0.28$ & $0.53 \pm 0.52$ & 5.16 & 0.009 \\
\hline
\end{tabular}

Bold values indicate statistically significance at $\mathrm{p}<0.05$.

$\mathrm{p}<0.05$ in one-way ANOVA. 
Table 4. Mean values \pm SD of taxon richness, abundance and relative abundance of higher taxa and the most abundant families.

$\begin{array}{ccccc} & \text { Good } & \text { Fair } & \text { Poor } & \text { F-ratio p-Value } \\ \text { Richness }^{\square} & 36.1 \pm 9.1 & 27.8 \pm 7.8 & 17.2 \pm 6.8 & 32.910<\mathbf{0 . 0 0 1}\end{array}$

Relative abundance (\%)

$\begin{array}{clllll}\text { Insects }{ }^{-} & 97.9 \pm 3.6 & 97.3 \pm 5.1 & 84.9 \pm 14.2 & 15.321<\mathbf{0 . 0 0 1} \\ \text { Ephemeroptera } & 39.3 \pm 14.4 & 49.1 \pm 21.1 & 36.7 \pm 23.7 & 2.501 & 0.090 \\ \text { Baetidae } & 13.4 \pm 11.1 & 16.2 \pm 15.3 & 8.2 \pm 10.7 & 2.591 & 0.082 \\ \text { Ephemerellidae } & 8.1 \pm 5.7 & 7.3 \pm 8.1 & 4.0 \pm 8.7 & 1.872 & 0.162 \\ \text { Heptageniidae }^{-} & 9.2 \pm 6.7 & 7.8 \pm 8.2 & 5.4 \pm 5.7 & 1.833 & 0.168 \\ \text { Plecoptera }^{-} & 3.6 \pm 3.8 & 2.0 \pm 3.9 & 0 & 7.634 & <\mathbf{0 . 0 0 1} \\ \text { Perlidae }^{-} & 1.4 \pm 1.5 & 0.9 \pm 2.2 & 0 & 5.311 & \mathbf{0 . 0 0 7} \\ \text { Trichoptera }^{-} & 23.2 \pm 14.8 & 17.4 \pm 12.5 & 6.2 \pm 7.5 & 12.463<\mathbf{0 . 0 0 1} \\ \text { Hydropsychidae }^{-} & 12.9 \pm 12.0 & 12.8 \pm 10.0 & 5.1 \pm 7.4 & 4.941 & \mathbf{0 . 0 1 0} \\ \text { Glossosomatidae }^{-} & 4.9 \pm 7.0 & 0.7 \pm 1.9 & 0 & 9.682 & <\mathbf{0 . 0 0 1} \\ \text { Chironomidae }^{-} & 13.9 \pm 14.6 & 15.3 \pm 12.7 & 31.1 \pm 21.7 & 7.602 & \mathbf{0 . 0 0 1} \\ \text { Coleoptera }^{-} & 6.4 \pm 4.9 & 3.4 \pm 3.9 & 5.1 \pm 13.4 & 0.696 & 0.502 \\ \text { Elmididae }^{-} & 4.9 \pm 4.7 & 2.7 \pm 3.6 & 2.6 \pm 6.9 & 1.311 & 0.276 \\ \text { Oligochaeta }^{-} & 0.8 \pm 2.2 & 0.7 \pm 1.8 & 7.2 \pm 11.7 & 6.376 & \mathbf{0 . 0 0 3} \\ \text { Mollusc }^{-} & 0.3 \pm 0.8 & 0.6 \pm 1.0 & 5.8 \pm 9.7 & 6.541 & \mathbf{0 . 0 0 3}\end{array}$

Bold values indicate statistically significance at $\mathrm{p}<0.05$.

$\mathrm{p}<0.05$ in one-way ANOVA. 
Table 5. Summary statistics of the forward selection procedure, showing significant environmental and spatial variables correlated with taxonomic (species) and functional (trait) structure. Adj. $\mathrm{R}^{2}=$ cumulative adjusted $\mathrm{R}^{2}$. The variables are presented in the order they were selected in the models.

\begin{tabular}{|c|c|c|c|c|c|c|c|}
\hline Variable & Adj $R^{2}$ & Pseudo-F & $\mathbf{p}$ & Variable & Adj $\mathbf{R}^{2}$ & Pseudo-F & $\mathbf{p}$ \\
\hline Catchment-scale & & & & Catchment-scal & & & \\
\hline$\%$ Agriculture & 0.118 & 10.266 & 0.001 & $\%$ Agriculture & 0.157 & 13.883 & 0.001 \\
\hline$\%$ Forest & 0.165 & 4.792 & 0.001 & $\%$ Grass & 0.200 & 4.611 & 0.009 \\
\hline$\%$ Open water & 0.197 & 3.651 & 0.001 & $\%$ Urban & 0.228 & 3.425 & 0.022 \\
\hline$\%$ Grass & 0.222 & 3.181 & 0.001 & & & & \\
\hline$\%$ Urban & 0.245 & 2.812 & 0.001 & & & & \\
\hline$\%$ others & 0.251 & 1.648 & 0.026 & & & & \\
\hline Reach-scale & & & & Reach-scale & & & \\
\hline $\mathrm{EC}$ & 0.098 & 8.524 & 0.001 & $\%$ Pebble & 0.219 & 20.31 & 0.001 \\
\hline $\mathrm{NO}_{3}$ & 0.132 & 3.629 & 0.001 & $\%$ Gravel & 0.282 & 6.976 & 0.005 \\
\hline CODmn & 0.152 & 2.560 & 0.001 & DO & 0.315 & 4.201 & 0.004 \\
\hline WT & 0.170 & 2.486 & 0.001 & Velocity & 0.345 & 4.122 & 0.008 \\
\hline Species $\mathrm{NH}_{4}$ & 0.187 & 2.336 & 0.001 Traits & $\mathrm{NO}_{3}$ & 0.374 & 4.007 & 0.009 \\
\hline$\%$ Pebble & 0.199 & 2.025 & 0.002 & MD & 0.390 & 2.589 & 0.045 \\
\hline $\mathrm{TP}$ & 0.209 & 1.711 & 0.022 & & & & \\
\hline DO & 0.218 & 1.710 & 0.015 & & & & \\
\hline Spatial factor & & & & Spatial factor & & & \\
\hline MEM3 & 0.068 & 6.033 & 0.001 & MEM 1 & 0.075 & 6.588 & 0.002 \\
\hline MEM 1 & 0.121 & 5.091 & 0.001 & MEM 21 & 0.141 & 6.264 & 0.005 \\
\hline MEM 2 & 0.155 & 3.665 & 0.001 & MEM 26 & 0.185 & 4.582 & 0.017 \\
\hline MEM 5 & 0.182 & 3.193 & 0.001 & MEM 8 & 0.206 & 2.761 & 0.040 \\
\hline MEM 4 & 0.202 & 2.677 & 0.001 & & & & \\
\hline MEM 21 & 0.217 & 2.164 & 0.004 & & & & \\
\hline MEM 8 & 0.227 & 1.825 & 0.011 & & & & \\
\hline MEM 26 & 0.235 & 1.700 & 0.031 & & & & \\
\hline
\end{tabular}

